\title{
An Overview of Functionally Graded Additive Manufacturing
}

Giselle Hsiang Loh (Department of Design, Brunel University, London, UK)

Eujin Pei (Department of Design, Brunel University, London, UK)

David Harrison (Department of Design, Brunel University, London, UK)

Mario D. Monzón (Universidad de Las Palmas de Gran Canaria, The Canary Islands, Spain)

\begin{abstract}
Functionally Graded Additive Manufacturing (FGAM) is a layer-by-layer fabrication process that involves gradationally varying the material organization within a component to achieve an intended function. FGAM establishes a radical shift from contour modelling to performance modelling by having the performance-driven functionality built directly into the material by strategically controlling the density and directionality of the substance or to combine materials together to produce a seamless monolithic structure. This paper presents a state-of-art conceptual understanding of FGAM, covering an overview of current techniques that can enable the production of FGAM parts as well as identifying current technological limitations and challenges. Possible strategies for overcoming those barriers are presented and recommendations on future design opportunities are discussed.
\end{abstract}

\section{Keywords}

Additive Manufacturing; Functionally Graded Additive Manufacturing; Functionally Graded Materials; Variable-property Fabrication; Multi-material Printing.

\section{Introduction and Definition}

Functionally Graded Materials (FGMs) are a class of advanced materials characterized by spatially variation in composition across the volume, contributing to corresponding changes in material properties in line with the functional requirements [1]. The multi-functional status of a component is tailored through the material allocation at microstructure to meet an intended performance requirement. Microstructural gradation contributes a smooth transition between properties of the material (Mahamood, 2017).

Additive Manufacturing (AM) is a solid freeform manufacturing technology that enables the direct fabrication of fine detailed bespoke component by accurately place material at set positions within a design domain. Throughout the years, AM technologies have expanded from making one-off prototypes to the creation of full-scale end-use parts driven by improved manufacturability. The technological advancement of today's AM systems enable the use of FGM, leading to the term Functionally Graded Additive Manufacturing (FGAM) which is a layer-by-layer fabrication technique that involves gradationally varying the material organization within a component to meet an intended function.

FGAM is a material-centric fabrication process that establishes a radical shift from contour modelling to performance modelling The advancement of $\mathrm{AM}$ technologies make it possible to strategically control the density and directionality of material deposition in a complex 3D distribution or to combine various materials to produce a seamless monolithic structure by changing deposition density and orientations (Oxman, 2011). The potential microstructural gradient compositions achievable by FGAM can be characterised into 3 types: (a) variable densification within a homogeneous composition; (b) heterogeneous composition through simultaneously combining two or more materials through a gradual transition; and (c) using a combination of variable densification within a heterogeneous composition. 


\subsection{Homogeneous compositions}

\section{Single-material FGAM}

Homogeneous FGAM composition creates porosity or density gradients by strategically modulating the spatial microstructure or morphology of lattice structures across the volume of a bulk material through the voxel approach [Aremu, 2017; Mahamood, 2017]. This method can also be termed as varied densification FGAM. The directionality, magnitude and density concentration of the material substance in a monolithic anisotropic composite structure contribute to functional deviations such as stiffness and elasticity.

\section{5\% Density 60\% Density 65\% Density}
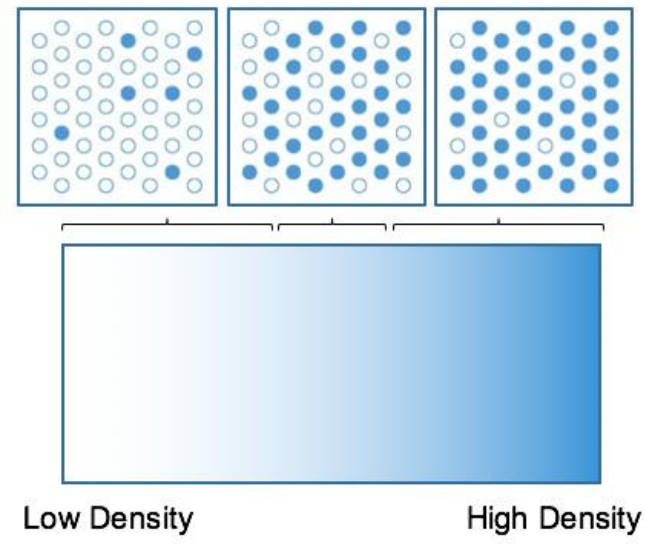

Figure 1: Varied densification FGAM

FGAM can be a biologically inspired rapid fabrication mimicking the structure of material found in nature such as the radial density gradients in palm trees, the spongy trabecular structure of bone or tissue variation in muscle. Varied densification FGAM enables lightweight structures by adjusting the lattice arrangement and varying the strut geometry to retain the structural strength but yet a reducing the overall weight [Aremu, 2017]. This can be exemplified in Figure 2, in which a 3D printed concrete fabricated using a modified 3D Printer that demonstrate the graded radial density concept of the cellular structures of the palm tree [Keating, 2015]. The gradual transition from a solid exterior to a porous core leads to an excellent strength-to-weight ratio, making the concrete lighter yet more efficient and stronger.
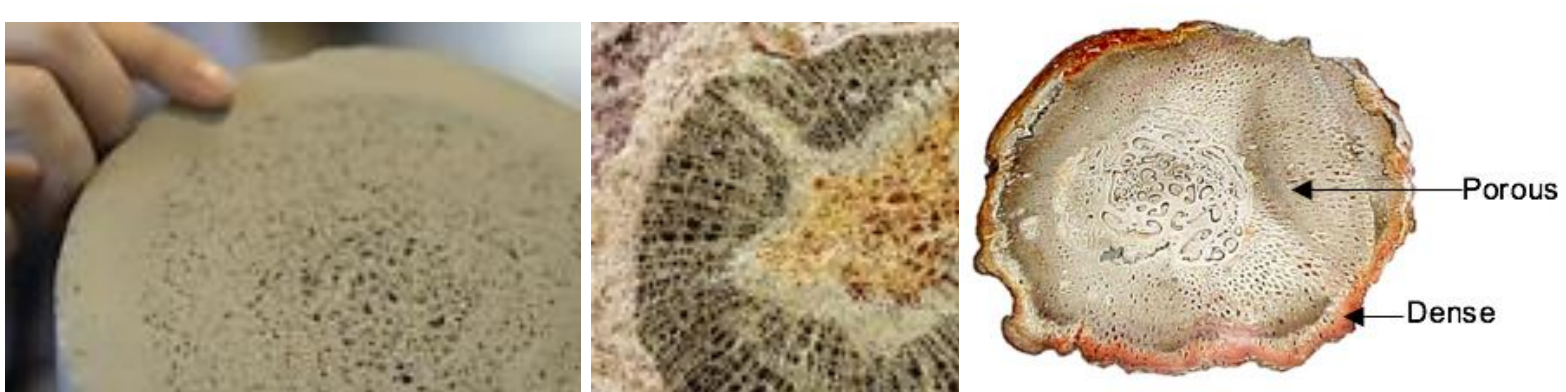

Figure 2: Varied densification FGAM concrete by Keating mimicking the radial density gradient of a palm tree [Keating, 2015]. 


\subsection{Heterogeneous compositions}

\section{Multi-material FGAM}

FGAM addresses the aspect of multi-materiality through an approach of dynamically composed gradients or through complex morphology. The geometric and material arrangement of the phases controls the overall functions and properties of the FGAM component. Multi-material FGAM seeks to improve the interfacial bond between dissimilar or incompatible materials (Figure $3 b$ ). Distinct boundaries can be removed through a heterogeneous compositional transition from a dispersed to an interconnected second phase structure, layered graded with discrete compositional parameters or smooth concentration gradients. Common failures such as delamination, cracks caused by the surface tension experienced by conventional multi-material additive manufacturing due to discrete change of materials properties can thus be avoided (Figure 3a) [Choi, 2011, Sirris, 2012]. In-plane and transverse stresses by different expansion coefficients at critical locations can also be largely reduced [T-Williams, 2016] while the residual stress distribution material properties can be improved and enhanced [Birman, 2007, Chauhan, 2016].

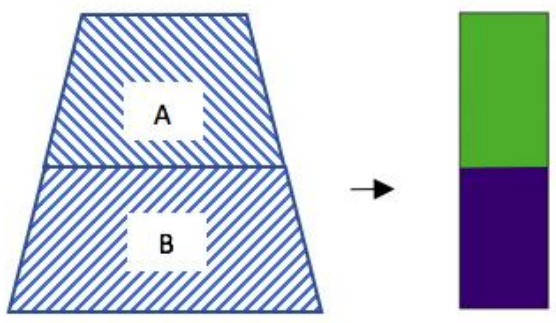

Figure 3a: Conventional MMAM

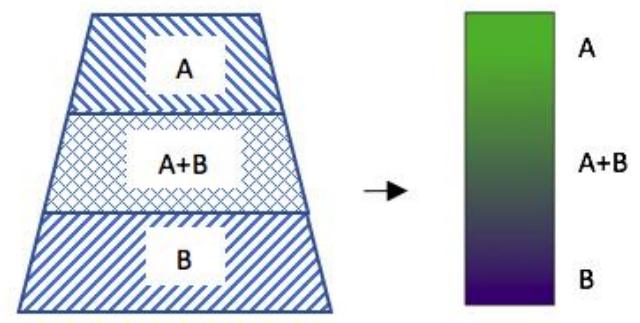

Figure 3b: MM FGAM (2 materials)

Figure 3: Conventional multi-material additive manufacturing versus multi-material FGAM.

By fusing one material to another material three-dimensionally using a dynamic gradient, the printed component can have the optimum properties of both materials (Figure 4). It can be transitional in weight, yet retaining its toughness, wear resistance, impact resistance or its physical, chemical or biochemical or mechanical properties [Hascoet, 2011, Kieback, 2003]. Heterogeneous mixtures of materials no longer need to compromise on its intrinsic properties to achieve the desirable properties of the component. Multi-material FGAM can also provide site-specific properties tailored at a small sections or strategic locations around pre-determined parts [Vaezi, 2013].
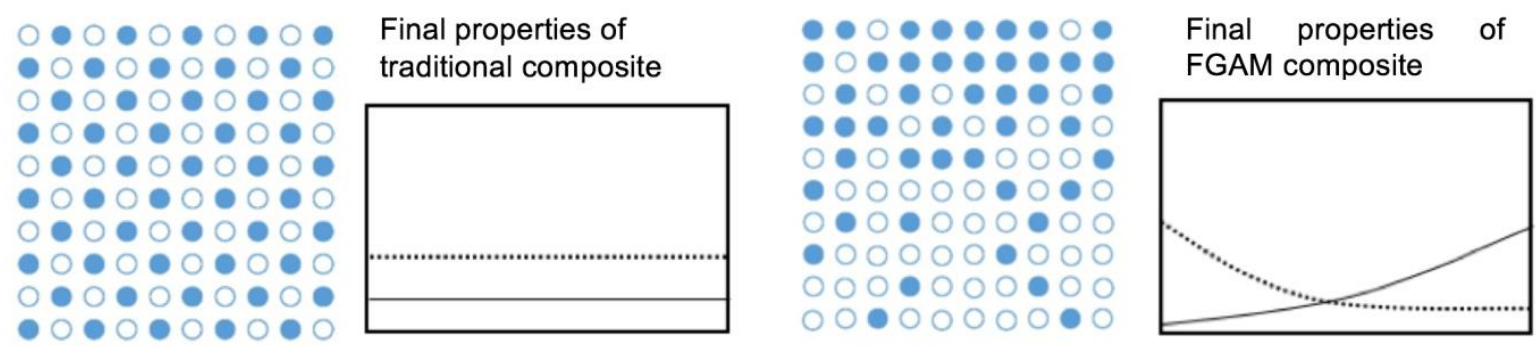

Figure 4: Traditional composite versus FGAM composite and schematic structures to illustrate the change in material properties in thermal conductivity (....) and elastic modulus (-) (Craveiro, et al, 2013). 
Figure 5 demonstrates a smooth and seamless transition between materials from $0 \%$ at one end to $100 \%$ to the other end in Multi-material FGAM. The continuous variation within the 3D space can be achieved by controlling the ratios in which two or more materials that are mixed during the deposition and before curing. However, the compositional variation must be controlled by the computer program [Vaezi, 2013, Mahamood, 2012]. Vaezi (2013) also argued that raw materials which are pre-mixed or composed prior to deposition or solidification should not be considered as Multi-material FGAM.
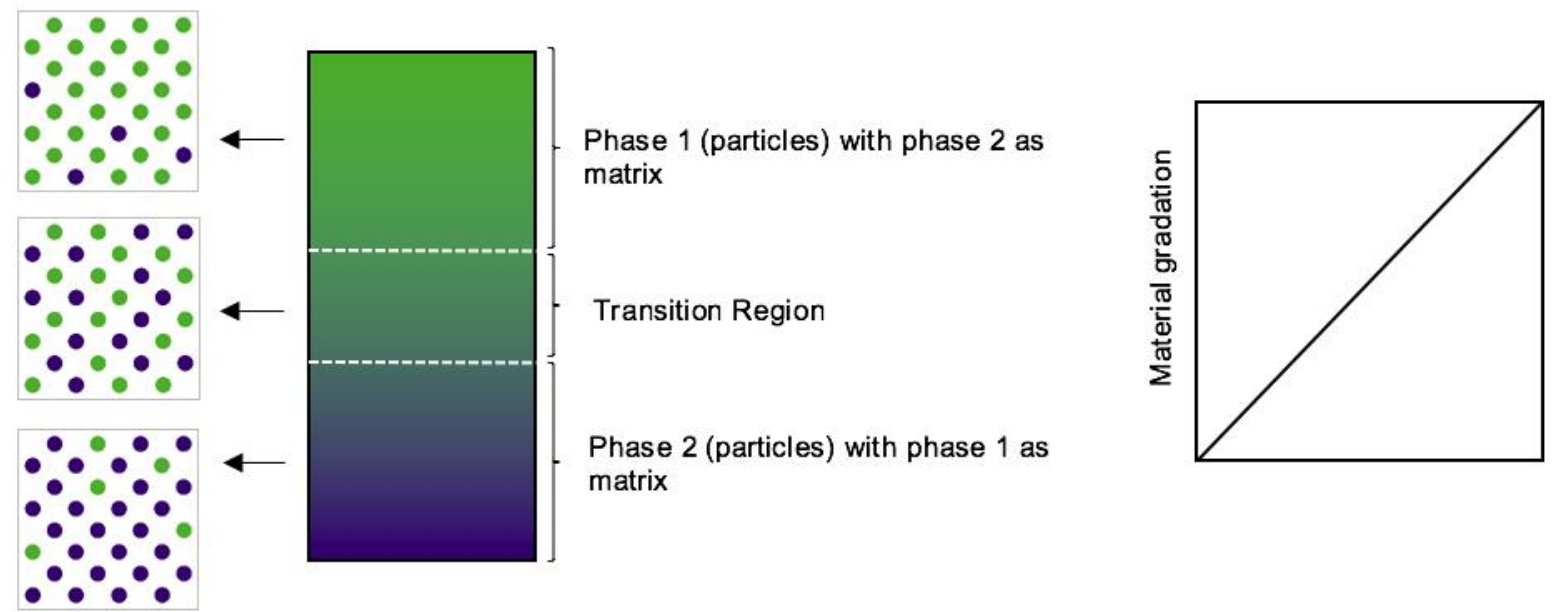

Figure 5: Multi-material FGAM with continuous graded microstructure between 2 materials.

The design of heterogeneous compositional gradients can be divided into 4 types: a transition between 2 materials (Figure 6), 3 materials or above (Figure 7), switched composition between different locations (Figure 8) or a combination of density and compositional gradation (Fig. 9).

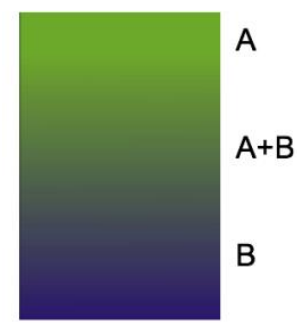

Figure 6: MM FGAM (2 materials) compositions

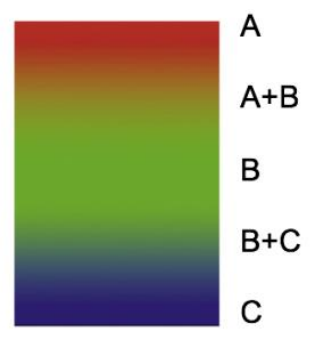

Figure 7: MM FGAM (3 materials)

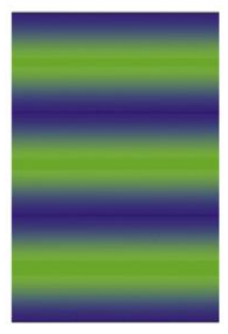

Figure 8: Switched

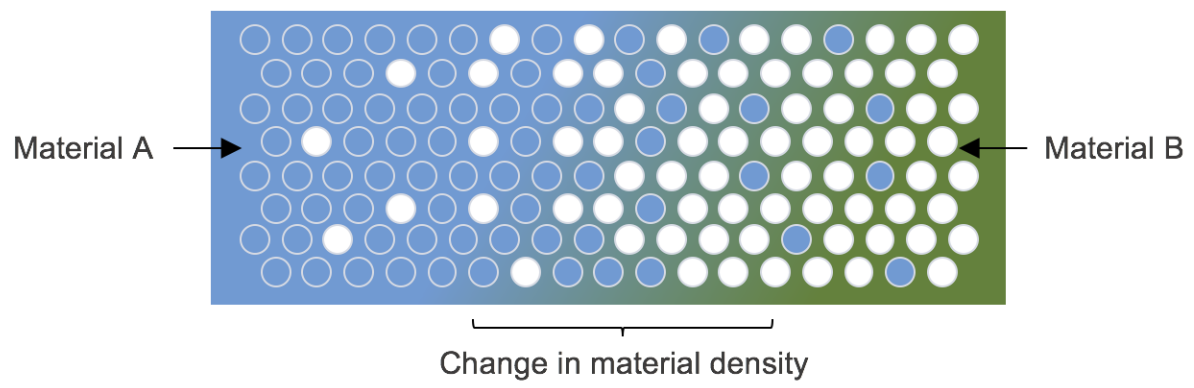

Figure 9: Combination of density and compositional gradation within a heterogeneous material. 
The key design parameters of FGAM include the dimension of the gradient vector, the geometric shape and the repartition of the equipotential surfaces. The features and functionality of the component are further determined by the direction of the gradient within the composition [Craveiro, 2013]. The design and types of the volumetric gradient can be classified according to 1D, 2D and $3 \mathrm{D}$ as illustrated in Figure 10, and distributing the materials uniformly or through special patterns.

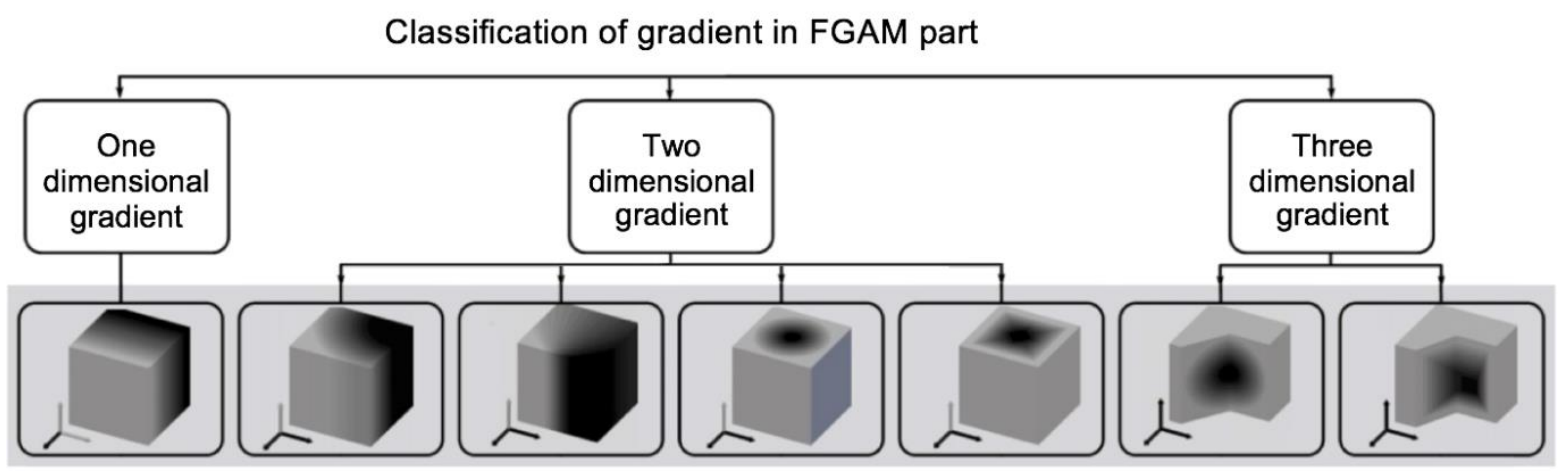

Figure 10: Types of gradients classification [Muller, 2012; Muller, 2014].

\section{The Design and Modelling of FGAM}

The use of FGAM requires good control of the toolpath based on a triptych "materialsproduct-manufacturing" approach (Muller, 2012). The manufacturing procedures for FGAM is relatively similar to the AM workflow, from solid model generation using CAD, slicing, conversion of the CAD file into .STL or an appropriate data exchange file format, verification of the STL data, determination of optimal orientation, support generation, toolpath definition, fabrication, and post-processing. However, the key difference is that FGAM places a higher priority towards the description and assignment of material properties and the behaviour of every voxel within the designed component (Figure 11).

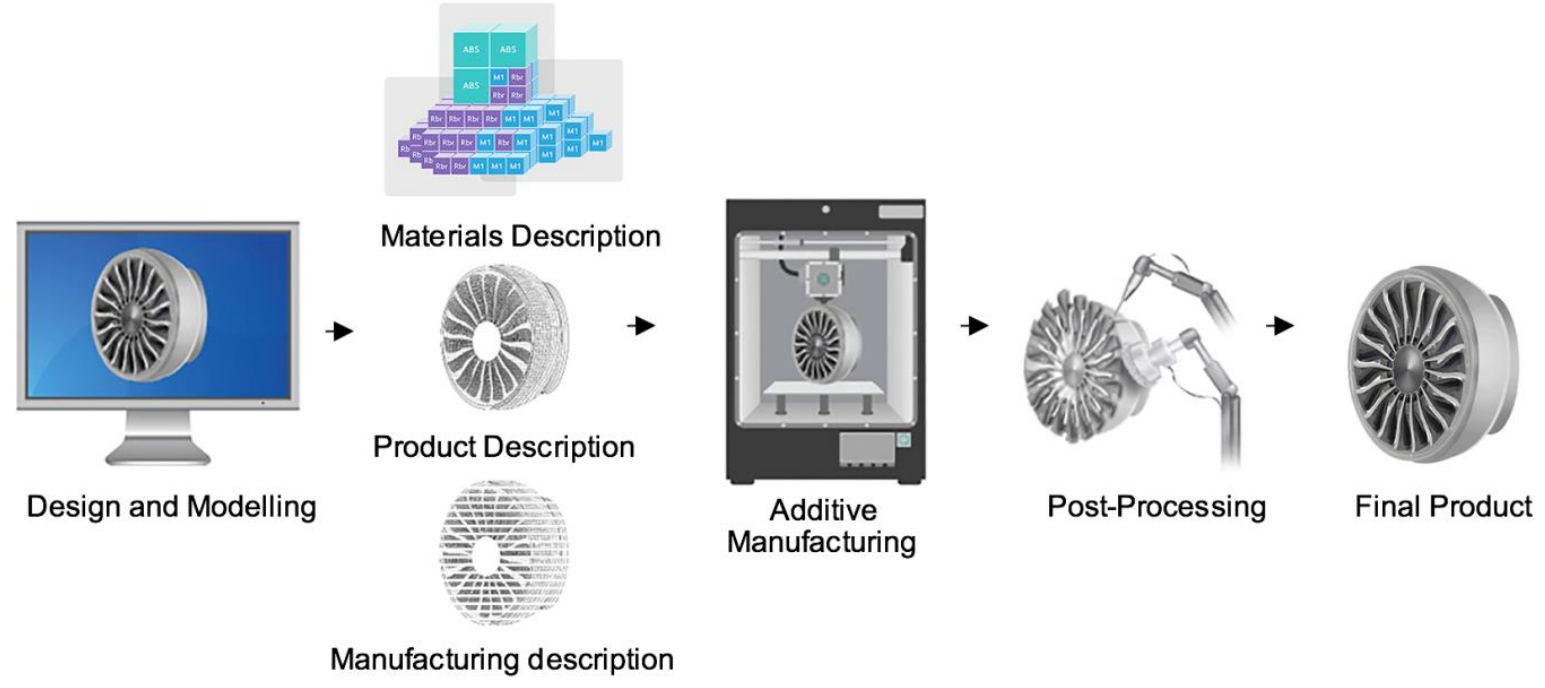

Figure 11: The FGAM process flow from design to manufacturing (Cotteleer, 2014; Muller, 2012; Xerox, 2017).

\begin{tabular}{|l|l|}
\hline Step & Process \\
\hline
\end{tabular}




\begin{tabular}{|c|c|c|}
\hline $\begin{array}{l}\text { Step 1: } \\
\text { Design and } \\
\text { modelling }\end{array}$ & $\begin{array}{l}\text { - } \text { Product concept } \\
\text { generation } \\
\text { - Computer aided } \\
\text { design for } \\
\text { manufacturing and } \\
\text { simulation } \\
\text { - Topology and infill } \\
\text { optimisation }\end{array}$ & $\begin{array}{l}\text { The mechanical function of the part is defined } \\
\text { by describing the fundamental attributes } \\
\text { including the geometry and material } \\
\text { composition. Some parts can be optimised by } \\
\text { the lattice or cellular structure. Other important } \\
\text { attributes include topology optimization, } \\
\text { gradient dimension or vector, the geometric of } \\
\text { equi-composition or equi-property surfaces, } \\
\text { the material characteristics, and mechanical } \\
\text { parameters before developing a modelling } \\
\text { scheme (Zhang, 2016). }\end{array}$ \\
\hline $\begin{array}{l}\text { Step 2.1: } \\
\text { Materials } \\
\text { description }\end{array}$ & $\begin{array}{l}\text { - } \text { Material selection and } \\
\text { microstructure } \\
\text { allocation } \\
\text { - Defining optimum } \\
\text { material properties } \\
\text { distribution } \\
\text { - Gradient classification } \\
\text { - Analysis of area void } \\
\text { density }\end{array}$ & $\begin{array}{l}\text { Material data that concerns the chemical } \\
\text { composition and characteristics of the part is } \\
\text { modelled. Digital simulation is used to } \\
\text { represent the materials, formulate a matching } \\
\text { epistemology for the material selection, } \\
\text { gradient discretization, volume of support, } \\
\text { residual stresses, etc. (Grigoriadis, 2015). The } \\
\text { void density needs to be taken into account in } \\
\text { the theoretical calculation. }\end{array}$ \\
\hline $\begin{array}{l}\text { Step 2.2: } \\
\text { Product } \\
\text { description }\end{array}$ & $\begin{array}{l}\text { Classification of the } \\
\text { part (geometry and } \\
\text { material repartition) } \\
\text { with mathematical } \\
\text { data. }\end{array}$ & $\begin{array}{l}\text { Mathematical data is used to identify an } \\
\text { appropriate manufacturing strategy and } \\
\text { process control. }\end{array}$ \\
\hline $\begin{array}{l}\text { Step 2.3: } \\
\text { Manufacturing } \\
\text { description }\end{array}$ & $\begin{array}{l}\text { Classify information } \\
\text { from step } 2.2 \text { into } \\
\text { slices and build } \\
\text { orientation }\end{array}$ & $\begin{array}{l}\text { The manufacturing strategy is determined } \\
\text { according to a triptych material-product- } \\
\text { manufacturing. The mathematical data from } \\
\text { product and material description are used to } \\
\text { define the slicing orientation, categorised as } \\
\text { planar or complex slices (Muller, 2012). }\end{array}$ \\
\hline $\begin{array}{l}\text { Step 3: } \\
\text { Additive } \\
\text { manufacturing }\end{array}$ & $\begin{array}{l}\text { - } \text { Manufacturing } \\
\text { strategy and process } \\
\text { plan determination. } \\
\text { - Paths classification } \\
\text { - NC Programming } \\
\text { - Process control and } \\
\text { monitoring }\end{array}$ & $\begin{array}{l}\text { This type of path strategy is defined and then } \\
\text { evaluated according to the geometry and } \\
\text { material repartition. Numerical Control (NC) } \\
\text { programming involves the generation of paths } \\
\text { and modification of process parameters using, } \\
\text { but not limited to G-code programming } \\
\text { language (Muller, 2014; Kulkarni, 2000). The } \\
\text { file is sent to the AM machine for the } \\
\text { production sequence to commence (Muller, } \\
2012 \text { ). }\end{array}$ \\
\hline $\begin{array}{l}\text { Step 4: } \\
\text { Post-processing }\end{array}$ & $\begin{array}{l}\text { - Part removal } \\
\text { - Heat and pressure } \\
\text { treatment } \\
\text { - Machining } \\
\text { - Surface treatment }\end{array}$ & $\begin{array}{l}\text { Post-processing ensures that the quality } \\
\text { aspects (e.g. surface characteristics, } \\
\text { geometric accuracy, aesthetics, mechanical } \\
\text { properties) of the printed part meets its design } \\
\text { specifications. AM post-processing methods } \\
\text { include, but not limited to, tumbling, machining, } \\
\text { hand-finishing, micromachining, chemical post- } \\
\text { processing, electroplating and laser }\end{array}$ \\
\hline
\end{tabular}




\begin{tabular}{|c|c|c|}
\hline & & micromachining (Kumbhar, 2016). \\
\hline $\begin{array}{l}\text { Step 5: } \\
\text { Final Product }\end{array}$ & $\begin{array}{l}\text { - Quality assurance } \\
\text { - Validation }\end{array}$ & $\begin{array}{l}\text { Experimental analysis such as non-destructive } \\
\text { testing, stress analysis or microscopic imaging } \\
\text { are carried out to validate the final product and } \\
\text { resultant part properties. }\end{array}$ \\
\hline
\end{tabular}

Table 1: Manufacturing methodology of FGAM.

\section{$3 \quad$ Limitations in Describing Materials}

Representing materials on top of the geometric information is significant for both single and multi-material FGAM. Defining the optimum material distribution function requires extensive knowledge of material data that includes the chemical composition, its characteristics and the manufacturing constraints (Muller, 2012) [Zhang, 2016]. The material selection for AM is still generally limited. At present, there are no design guidelines on material compatibility, mixing range for materials with variable and non-uniform properties and a framework for optimal property distribution such as choice of spatial, gradient distribution and the arrangement of transition phases is lacking [T-Williams, 2016]. For example. the design of the gradient and the arrangement of transition phases are still not fully understood and only very few commercial software exists that can simulate the design of the gradient such as Autodesk Monolith which is a voxel-based modelling engine for multi-material 3D printing. Therefore, it is difficult for designers or engineers without a background in material science to fully utilise the potential of FGAM.

When generating graded components of high to low strength, the changing material properties brought about by modifications to the microstructure have to be carefully measured and quantified. T-Williams [2016] suggested two useful approaches to model the response of functionally graded components using the exponential law idealisation and material elements "Maxels". Finite Element Method (FEM) of analysis can also be used to show and suggest an optimised set of elements under pre-determined circumstances to provide a better understanding of how the material properties will behave (e.g. ABAQUS).It is crucial to understand the differences between the predicted and actual components resulting from FGAM. The distribution of chemical components and its material properties of the manufactured component may potentially deviate from the actual production material due to the variability in interaction of the different materials at different operating conditions [Zhang, 2016]. For example, physical and technical factors such as macro segregation of the solutes during solidification and poor process control can lead to variable tolerances and inferior parts being produced. This can be reduced through in-situ monitoring during the build process. Design rules and methods by knowing the required mix of properties, the required arrangement of phases, and compatibility of materials have to be established to avoid undesirable results. Knowledge of the "processing-structure-property" relationship can be gained through shared databases as a catalogue of material performance information [Mahamood, 2017]. Basyam [2000] suggested that information including material composition, functions and applications should be established to assist designers in selecting the ideal material composition based on topological and geometrical changes in their design. Comotti [2017] also suggested the "function-behaviour-structure" FBS ontology [Gero, 2004] can be applied to model, calculate and predict the behaviour of a functional graded component using 8 elementary steps including formulation, synthesis, analysis, evaluation, documentation and reformulation steps (Figure 12). 


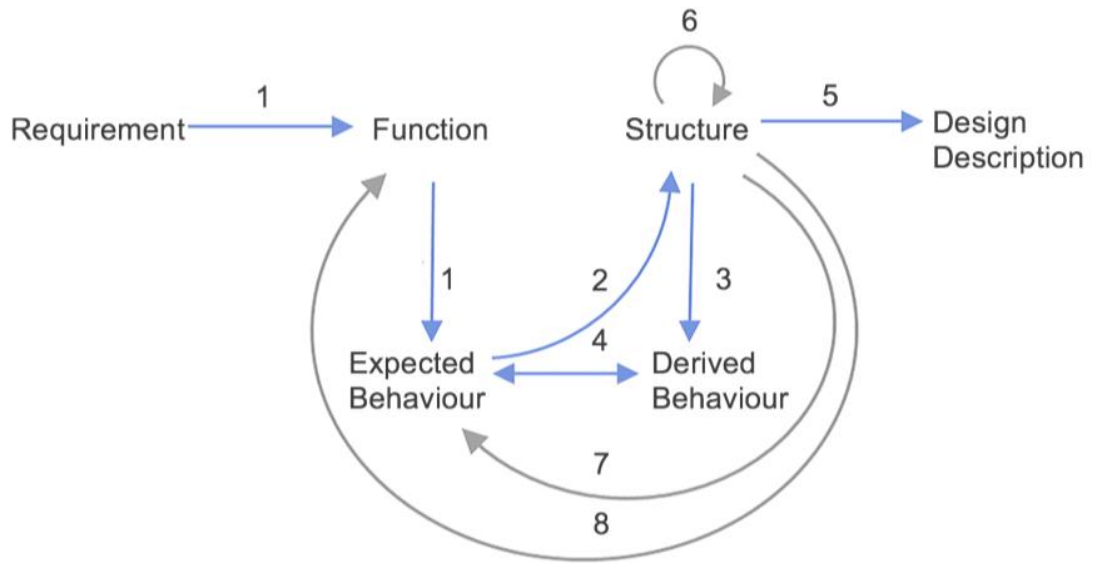

Figure 12: 8 steps in the function-behaviour-structure (FBS) framework that can be implemented to calculate the behaviour of FGM component [Gero, 2004].

\section{Current FGAM Software Limitations}

Modern information technologies in Computer-Aided Design has progressed with the provision of a multitude of file formats for the 3D model to communicate with the AM system. The common 4 geometric representation techniques in CAD include boundary representations (B-rep), constructive solid geometry (CSG), spatial decomposition and function representation (F-rep) [Kumar, 1999; Requicha, 1980]. B-rep and F-rep based methods represent the geometry of the $3-D$ form without describing the internal structure and material information of the component whereas parallel representations (PR) including spatial decomposition based PR [Doubrovski, 2015], constructive solid geometry (CSG) based PR \{Shin, 2001\} and hierarchy based PR [Kou, 2005] describe both geometry and material. FGAM requires a new approach of computational modelling that embrace the notion of self-organization [Richards, 2016]. It requires a new approach of Computer-AidedEngineering (CAE) analysis that can specify, model and manage the material information for Local Composition Control (LCC). Completely new approaches to slicing, analysing and preparing FGAM fabrication are mandatory. New AM software processes should be able to strategically control the density, directionality and allocation of material substances in a logical distribution throughout the generation of the FGAM model (Duan, 2014). Richards [2014] first proposed a computational approach of using CPPN (Compositional Pattern Producing Network) encodings and a scalable algorithm using NEAT (Neuroevolution of Augmented Topologies) to embed functional morphologies and macro-properties of physical features using multi-material FGAM through voxel-by-voxel descriptions by a function of its Cartesian $(x, y, z)$ coordinates (Figure 13a and 13b) [Pasko, 1995].
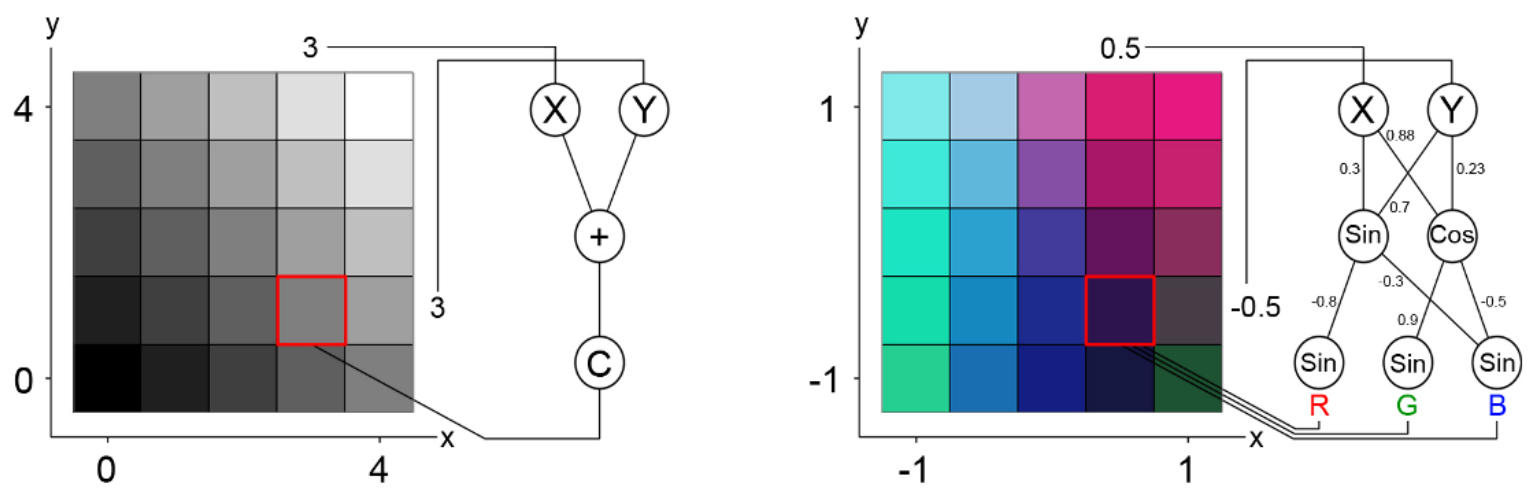

Figure 13a: Simple gradient pattern generated by summing the $x$ and $y$ coordinates of each pixel to generate a colour: $\mathrm{C}$. Figure 13b: CPPN generated pattern. The equation above shows the calculation of the voxel bordered in red [59]. 
At present, the conversion of voxel model from a common geometric format (i.e. STL file) for FGAM is computationally demanding and difficult to achieve trimmed lattices with highly refined details [Aremu, 2016]. As a solution, Richard (2018) introduced an alternate designsupporting system to represent material-geometry-topology with a volumetric texture map. Voxels models are algorithmically generated. Necessary modifications can thus be amended manually on voxels, and then compiled back into the texture description to allow changes at different scales. The GradCAD Voxel Print tool currently under development by Stratasys can become a potentially valuable software to support FGAM.

Another vital element of the AM software process is the "slicing" program to support parametric toolpath and related commands for the AM system (Steuben, 2016). Novel approaches to slice, analyse and prepare a FGAM component for fabrication is needed. Steuben (2016) presented a slicing algorithm based on the generation of toolpaths derived from arbitrary heuristics-based or physics-based fields. Hascoet (2011) established a set of mathematical formulations for the slicing of four possible typologies of bi-material gradient. Each class of typology has an associated part orientation strategy that can be implemented for FGAM. Wu (2008) proposed the use of material-resample with geometric constraints (MRGC) that offer another alternative for slicing FGAM parts.

\section{Potential Data Exchange Formats to support FGAM}

The common data format recognised by most AM technologies is usually a triangular facet model represented by polygonal meshes. The STL file and OBJ file format describe only the surface geometry without any material and property information. There are also several data exchange formats - AMF (Additive Manufacturing Format), FAV (Fabricatable Voxel), SVX (Simple Voxels) and 3MF (3D Manufacturing Format) that may be potentially suitable for the production of FGAM parts, containing information about the material gradient and microscale physical properties beyond a fixed geometric description.

AMF - ISO and ASTM have endorsed a standard format called the Additive Manufacturing Format (AMF, ISO/ASTM 52915:2016), that is an XML-based format capable of storing colour, materials, lattices, duplicates and constellations of the volumes that make up the object. The AMF File Format can be generated through SolidWorks, Inventor, Rhino and Mesh Mixer. AMF provides a suitable platform for FGAM including material specification, mixed and graded materials and sub-structures, and newer materials can be defined as compositions of other materials as well as its porousity. FGAM characteristics can be defined in the current AMF 1.2 specification through three different modalities: Functional representation, 3D texturing or volume texturing and voxel representation. The AMF file contains a provisional <voxel> node which aims to support voxel-based representation. While all three representations are described in the AMF 1.2 standard, each can be effectively sliced or exploited to support multiple functionally graded manufacturing modalities. The ISO/ASTM TC261/JG64 committee currently leads activities to leverage existing AMF 1.2 solid modelling features and to enable their use in further AMF format revisions, including, but not exclusive to FGAM.

FAV - The FAV format comprises digital information required for fabricating parts in a threedimensional space, for both the exterior and interior of an object including its colours, materials, and connection strength through Voxels [55]. Each Voxel can be expressed with various attribute values, including colour information and material information. Users can freely model and effectively manage the complex internal structures and attributes by controlling the relationships between each independent voxels. The FAV file format allows the user to design (CAD), analyse (CAE), and inspect (CAT) 3D model data seamlessly in 
an integrated manner without having to convert data. The FAV data format allows voxel data to be used for physical simulations, such as deformation from external forces (Figure 14).

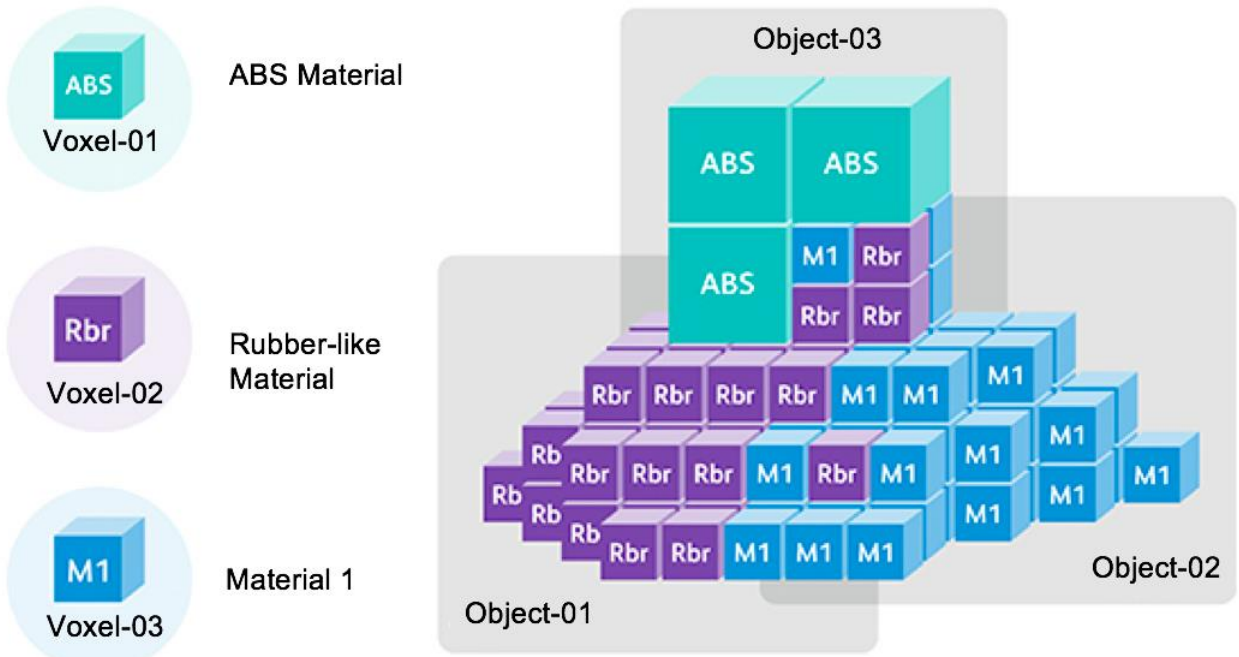

Figure 14: A conceptual diagram showing voxels arrangement of 3 different types of materials (ABS Material, Rubber-like Material and Material 1) within a 3D form using the FAV format (Xerox, 2017).

SVX - SVX (Simple Voxels) is a voxel transmittal format to carry voxel-based model for 3D printing. The basic format of SVX is a ZIP file composed of a series of image slices and a manifest.xml file. The design of SVX by Shapeways prioritises the need for a simple definition, ease of implementation and file extensibility. The aim is to convert voxels like the triangles in STL files, but still being able to contain information on material allocation, density, RGB colour or custom data that can be used for another variable (Duann, 2014; AbFab 3D, 2014).

3MF - The 3D Manufacturing Format (3MF) is an XML-based open format developed by the 3MF consortium that can represent the physical object's description in a mark-up format with richer external and internal information, aiming to be across-compatible for multiple AM system [3MF Consortium, 2016]. Although its push is for mainstream industry adoption, 3MF does not support solid modelling (higher-order representations) such as B-Rep, NURBS and STEP.

\section{AM Technologies for FGAM}

At present, not all AM technologies are capable of using FGMs. Current AM methods as shown in Table 2 are reported to have successfully produced FGAM components. They include material extrusion, direct-energy deposition, powder bed fusion, sheet lamination and PolyJet technology.

\begin{tabular}{|l|l|l|l|l|}
\hline $\begin{array}{l}\text { AM } \\
\text { Process }\end{array}$ & $\begin{array}{l}\text { Power } \\
\text { source }\end{array}$ & Description & $\begin{array}{l}\text { Supporting Techniques } \\
\text { for FGAM }\end{array}$ & Material \\
\hline $\begin{array}{l}\text { Material } \\
\text { extrusion }\end{array}$ & $\begin{array}{l}\text { Thermal } \\
\text { Energy }\end{array}$ & $\begin{array}{l}\text { Material selectively } \\
\text { is dispensed through } \\
\text { a nozzle or extruder. }\end{array}$ & $\begin{array}{l}\text { Fused deposition } \\
\text { modelling (FDM) } \\
\text { Freeze-form Extrusion } \\
\text { Fabrication (FEF) }\end{array}$ & $\begin{array}{l}\text { Thermoplastics, } \\
\text { ceramic slurries, } \\
\text { metal pastes }\end{array}$ \\
\hline Powder & High- & Feedstock is & Selective Laser Sintering & Polyamides or \\
\hline
\end{tabular}




\begin{tabular}{|l|l|l|l|l|}
\hline bed fusion & $\begin{array}{l}\text { powdered } \\
\text { laser beam } \\
\text { Electron } \\
\text { beam }\end{array}$ & $\begin{array}{l}\text { deposited and } \\
\text { selectively fused by } \\
\text { means of a heat } \\
\text { source or bonded by } \\
\text { means of an } \\
\text { adhesive to build up } \\
\text { parts. }\end{array}$ & $\begin{array}{l}\text { (SLS), } \\
\text { Direct Metal Laser } \\
\text { Sintering (DMLS), } \\
\text { Selective Laser Melting } \\
\text { (SLM), } \\
\text { Selective Mask Sintering } \\
\text { (SMS), } \\
\text { Electron Beam Melting } \\
\text { (EBM) }\end{array}$ & $\begin{array}{l}\text { polymer, } \\
\text { atomized metal } \\
\text { powder, ceramic } \\
\text { powder. }\end{array}$ \\
\hline $\begin{array}{l}\text { Directed } \\
\text { energy } \\
\text { deposition }\end{array}$ & $\begin{array}{l}\text { Laser } \\
\text { beam }\end{array}$ & $\begin{array}{l}\text { Thermal energy is } \\
\text { used to fuse } \\
\text { materials by melting } \\
\text { as they are being } \\
\text { deposited. }\end{array}$ & $\begin{array}{l}\text { Laser Engineering Net } \\
\text { Shape (LENS), } \\
\text { Directed Metal } \\
\text { Deposition (DMD) }\end{array}$ & $\begin{array}{l}\text { Molten metal } \\
\text { powder }\end{array}$ \\
\hline $\begin{array}{l}\text { Sheet } \\
\text { lamination }\end{array}$ & $\begin{array}{l}\text { Laser } \\
\text { Beam }\end{array}$ & $\begin{array}{l}\text { are bonded together } \\
\text { and selectively cut in } \\
\text { each layer to create } \\
\text { a desired 3D object. }\end{array}$ & $\begin{array}{l}\text { Laminated Object } \\
\text { Material (LOM), } \\
\text { Ultrasonic Consolidation } \\
\text { (UC) }\end{array}$ & $\begin{array}{l}\text { Plastic film, } \\
\text { metallic sheet, } \\
\text { ceramic tape }\end{array}$ \\
\hline $\begin{array}{l}\text { Material } \\
\text { jetting }\end{array}$ & $\begin{array}{l}\text { Photo of build } \\
\text { curing } \\
\text { selectival are } \\
\text { layer by layer. }\end{array}$ & $\begin{array}{l}\text { PolyJet Technology } \\
\text { (PJT) }\end{array}$ & $\begin{array}{l}\text { Photopolymer } \\
\text { digital materials }\end{array}$ \\
\hline
\end{tabular}

Table: Supporting additive manufacturing technologies for FGM and its classifications with referenced to ISO/ ASTM (ISO, 2015).

\subsection{Material Extrusion}

Fused Deposition Modelling (FDM) systems are capable of having multiple extruders, each carrying a paste of material (Mason, 2009). The different materials are subsequently sent to a static mixer to be made into a homogeneous paste (Figure 15).
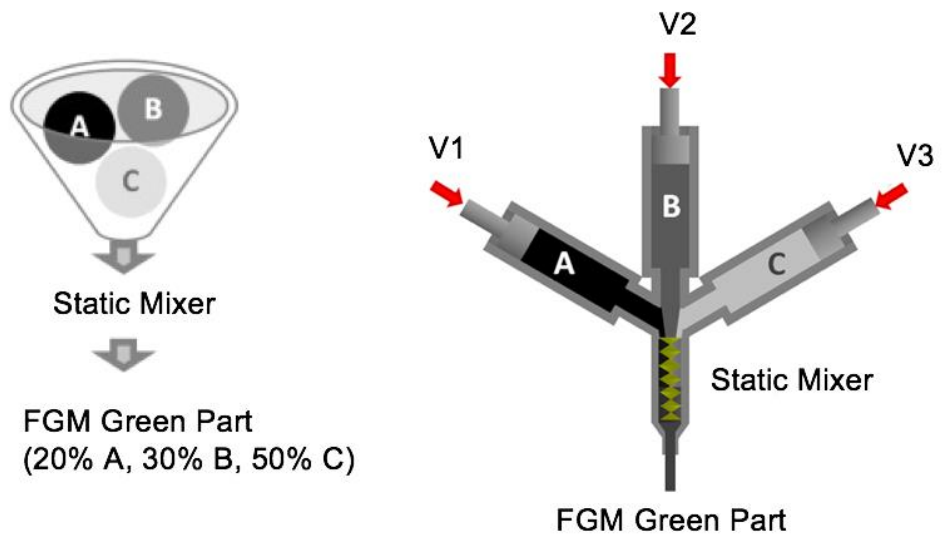

Figure 15: Schematic diagram of a static mixer and triple extruder of FEF system [26].

The deposition directions of each lamination and gap sizes between filaments are the principal manufacturing parameters that can be used to control the mechanical properties $(\mathrm{Li}$, 2002). Li (2002) fabricated two identically shaped FDM models but with varied deposition densities, orientation, bonding between ABS filaments and voids to demonstrate the differences in stiffness along the horizontal axis (Figure 16a and 16b). 

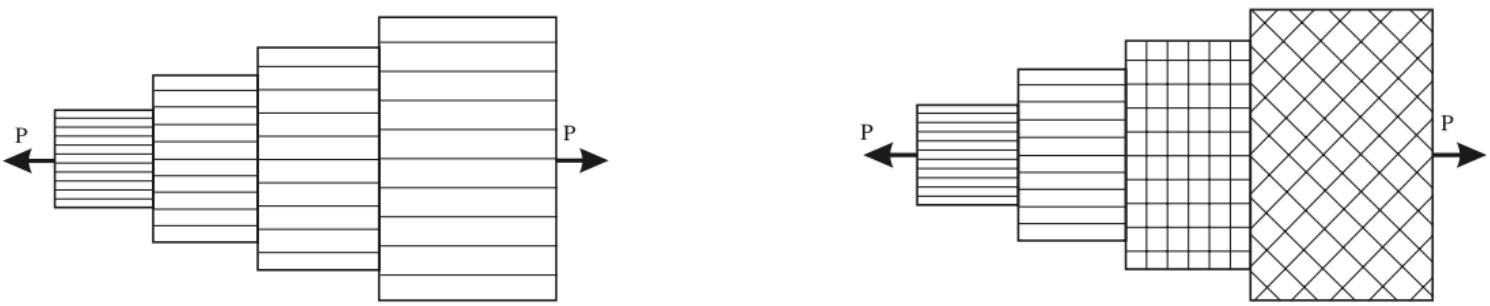

Figure 16a: Unidirectional deposition. Figure b: Multi-directional deposition strategies for each portion [Li, 2002].

Srivastava [2015] looked into the process control parameters in FDM that influenced the properties of functionally graded ABS parts, including the raster width, contour width, air gap, and raster angle. This framework can be extended for modelling and simulating the functionally graded FDM components for different load conditions.

\subsection{Powder Bed Fusion}

The use of Powder-Bed Fusion methods such as Selective Laser Sintering (SLS) can produce complex components with a spatially varied mechanical property if the correct powder-delivery method is used. Chung and Das [2008] used SLS to fabricate functionally graded polymer nanocomposites structures of Nylon-11 composites with various volume fractions of $15 \mathrm{~nm}$ fumed silica nanoparticles (0-30\%) as presented in Figure 17. The SLS processing parameters for different compositions were developed using the Design of Experiments (DOE) approach which is a systematic method to determine the relationship between factors affecting a process and the output of that process. The densities and microstructures of the nanocomposites were examined by optical microscopy and transmission electron microscopy (TEM). The tensile and compressive properties of each composition were then tested. Those properties exhibit a nonlinear variation as a function of filler volume fraction. The experimental work by Trainia [2008] and Sudarmadji [2011] also demonstrated an effective use of SLS technology being capable of producing graded porosity of Ti-6Al-4V alloy implants and scaffolds that closely match with human bone structures.

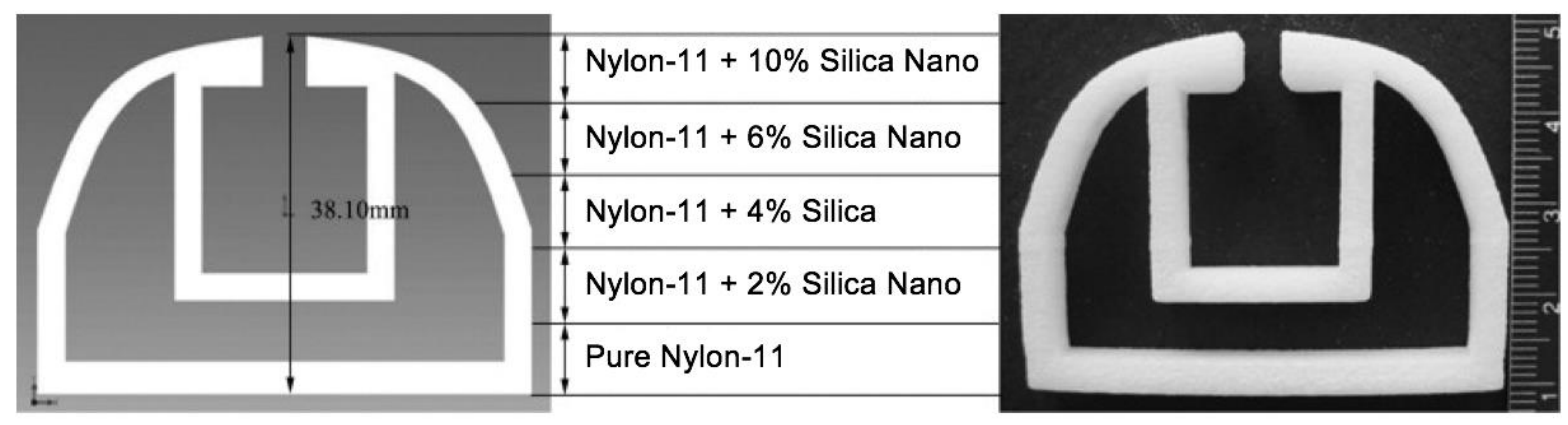

Figure 17: Compliant gripper. 7.62mm each layer [Mumtaz, 2007].

Zhou et al (2013) developed a mask-image projection system based on stereolithography (MIP - SL) to overcome the shortcoming of a single vat SLA technique (Figure 18). Switchable resin vats and micro-mirror devices (DMD) were installed to project mask images onto resin surfaces to build a multi-material component in a systematic way, thus capable of using different materials through a single build process. 


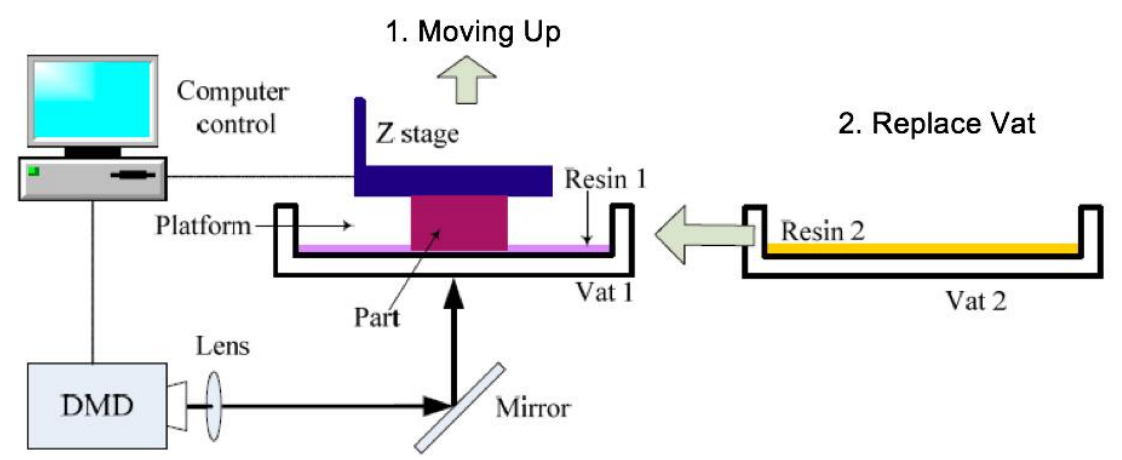

Figure 18: Mask-image projection system based on Stereolithography (MIP - SL) using bottom-up projection by Zhou et al [Zhou, 2013].

Selective Laser Melting (SLM) is a potential technique that can be used to fabricate functionally graded metal components. A heterogeneous metal composition can be achieved using multiple feeders. Mumtaz et al [2007] fabricated a FGM component blending Waspaloy and Zirconia materials using high powered laser. A particular strength of SLM is its ability to manufacture components incorporating periodic lattices. Maskery (2016) studied the relationships between the lattice geometry and the mechanical behaviour of Al-Si10-Mg lattices of uniform and graded densities together with the crushing behaviour of the FGM under quasi-static loading. A heat treatment framework for fabricating lightweight gradedlattice structure using SLM has been established based on his study.

Fraunhofer IGCV also presented a prototype-level of successive allocation and solidification of two materials within one component using a multi-material FGAM part of Copper-ChromeZirconia and Tool Steel being achieved by solidifying material spot-wise without mixing the materials before the process and also in-situ (Figure 19) [Anstaett, 2017].

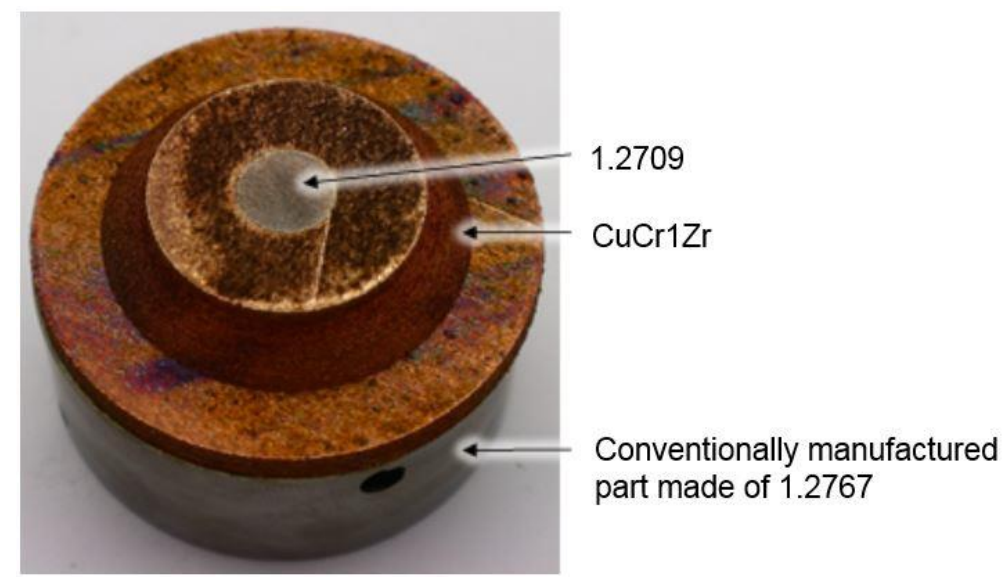

Figure 19: Multi-material FGAM part of Copper-Chrome-Zirconia and Tool Steel 1.2790 produced by Anstaett (2017) using laser-based powder bed fusion (note: 1.2709 is embedded cone-shaped into the CuCr1-Zr cone).

Lastly, FGM parts with good mechanical properties can be fabricated through EBM [Chua, 2014]. According to Gibson [2017], EBM-built parts have low residual stress due to the elevated build temperature being used. This theory is exemplified in the simulation study by Tan [2015] on building thickness-dependent microstructures for electron-beam melted Ti$6 \mathrm{Al}-4 \mathrm{~V}$ titanium alloy. 


\subsection{Directed-energy deposition}

Laser metal deposition process (LMD) is an important direct-metal deposition technology commonly used in product remanufacturing [Mahamood, 2017]. Directed Energy Deposition (DED) technologies have the ability to modify, repair, reinforce components or add materials to existing base structures from a 3D CAD model in one single process, which were not achievable with other AM technologies [Gibson, 2010]. The laser-based DED can be used to fabricate metallic parts with a gradient in composition by adjusting the volume of metallic powders delivered to the melt pool as a "function of position" [Caroll, 2016]. For example, Carroll [2016] successfully conducted a thermodynamic computational modelling approach for the production of FGM under an Argon atmosphere made up of 304L stainless steel incrementally graded to Inconel 625 using the DED technology through the RPM 557 Laser Deposition System. The designed system allows up to four powders to be added to the build during fabrication and the volumetric fraction of each powder can be altered by approximately $1 \%$ per deposited layer. The graded composition shown in Figure 20 is fractioned through 63 layers of approximately $0.5 \mathrm{~mm}$ tall built by a $910 \mathrm{~W}$ YAG laser with a hatch angle of $60^{\circ}$.
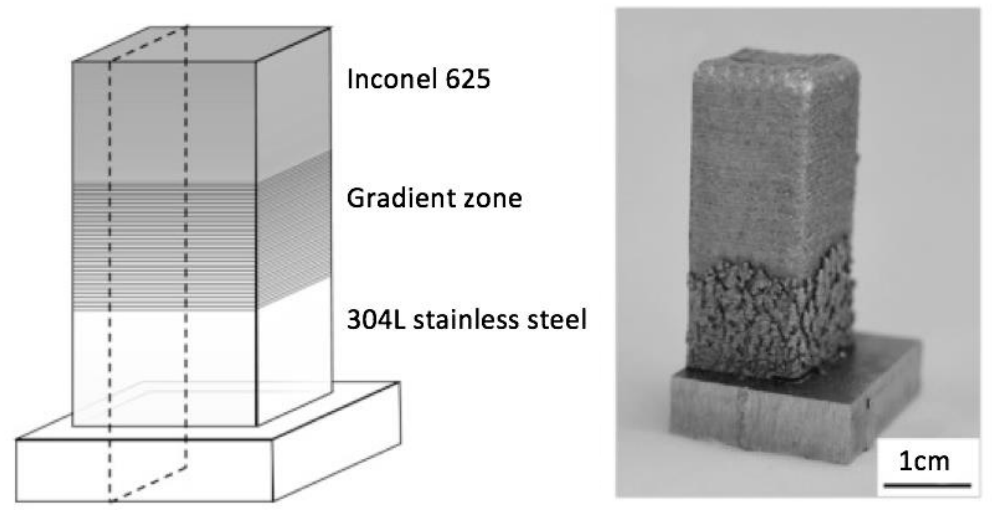

Figure 20: Schematic and photograph of gradient alloy specimen by Carrol [Caroll, 2016]. The dotted line shows where the part was sectioned for analysis.

\subsection{Sheet lamination}

The study by Kumar [2010] exemplified the production of FGM through ultrasonic consolidation using stainless steel, Al and Cu foil (Figure 21).
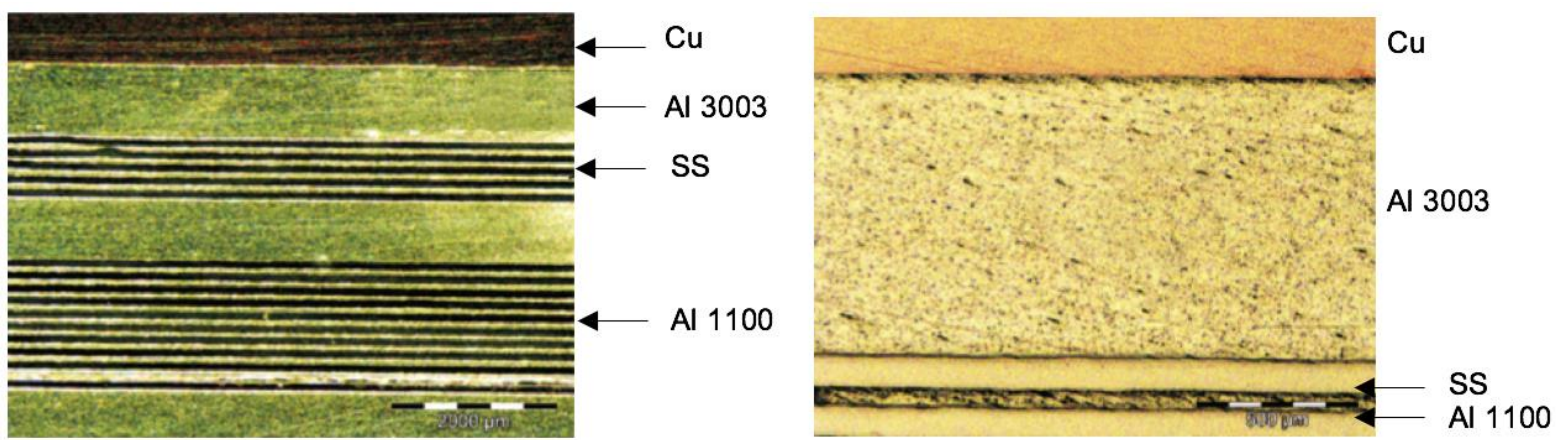

Figure 21: FGM produced through ultrasonic consolidation process and metallography [Kumar, 2010].

\subsection{Material Jetting}

PolyJet can incorporate the widest variety of colours and materials into a single print among all AM technologies. Applications like flexible over-moulding of rigid structures can be 
realised easily in a single print [Stratasys, 2017]. For instance, rubber-like parts can be printed with Shore hardnesses ranging from 27 to 95 . With its wide range of a digital material bank, functionally graded composite parts can have up to 82 different material properties. Speciality materials with unique properties are also available for particular applications such as biocompatibility for medical and dental applications. All possible combinations are preconfigured and selected in the Objet Studio and PolyJet Studio Software [Stratasys, 2017]. According to Figure 22, it is possible to achieve the colour gradient of yellow to magenta by merging a translucent rubber-like material Tango Plus together with two rigid and opaque materials, Vero Magenta and Vero Yellow. The graded intensity increases while the intensity and opacity of the colour fades.

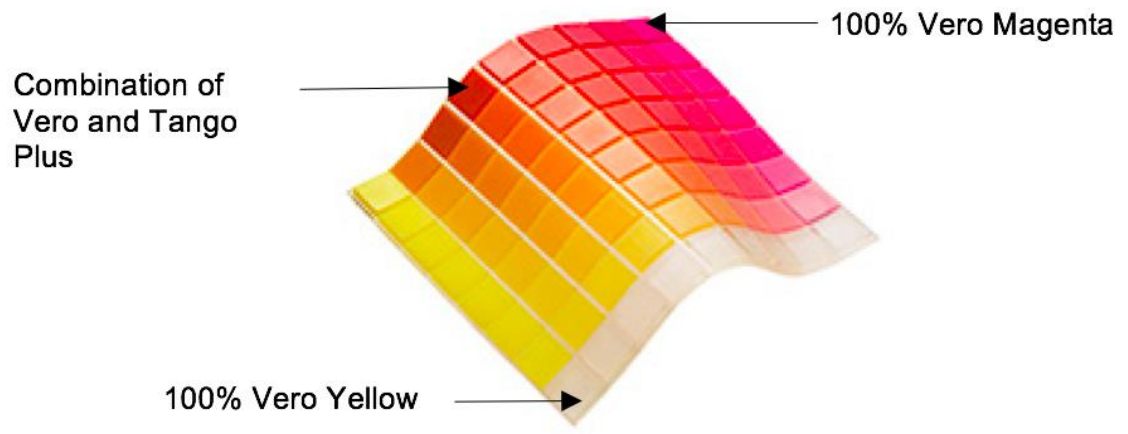

Figure 22: The hue of the palate demonstration by Stratasys [2017].

\subsection{Challenges for current AM technologies}

AM components are still prone to high internal and external defects, and poor control over tolerances. Due to limited regulation and a weak understanding of operational variables, the part quality and surface finishing standard can vary largely between batches or type of machines (Tofail, 2017). Fabricating of FGAM parts with complex internal structures and precise distribution of constituent phases in a microstructure level means that the delivery speed, accuracy and effectiveness of swiping materials between layers have to be improved for FGAM (Vaezi, 2013). Commercial available AM technologies still operate predominantly on isotropic materials, focusing on a basic geometric description and assigning single materials to build the entire component. Material characterization is the foremost challenge for FGAM processes that requires a high level in-situ measurements (Tofial, 2017). Although there an established modelling framework to demonstrate the approach of variable property gradient printing, there remains a need to look into the procedures and protocols that can guarantee a more reliable and predictable outcome, especially dealing with distribution of materials with constituent phases and transitioned properties throughout the structure [Birman, 2007], as well as considerations about the material choices, platform structure, and fabrication speed to support FGAM in an economical way [Lim, 2011]. In order to move to functional FGAM parts, a novel material delivery system must be developed. For instance, FDM suffers from inconsistent material mixing as present extrusion units are split into two or more separate systems. Materials cannot be blended to form other materials with any composition ratio using conventional round nozzles (Oxman, 2012). The spindle output channel has to be modified to communicate directly with the extrusion system controller (Oxman, 2012). 


\section{Conclusion}

This paper has presented a conceptual understanding and the process of FGAM from design to manufacture. FGAM technologies present a huge potential for designers and engineers to fabricate variable-property structures by strategically controlling the density of substances and the blending of materials. As this technology matures and applications increase, future work will focus on the tailoring ratios of aggregates, foaming agents, or bioprinting of scaffolds and bio-inks using FGAM. Another foreseeable radical shift of FGAM is the use of multiple stimuli-responsive materials, in which the manufactured component can undergo a geometrical transformation from one shape to another when triggered by appropriate stimuli (Tibbits, 2013a). FGAM can tailor the microstructure properties of a 4D Printed component to create more sophisticated geometrical transformations by strategically controlling the density and directionality of stimuli-responsive materials. It can also improve the lamination of heterogeneous smart compositions, and even disregard the material properties of being active or non-active. Although the potential of FGAM for future manufacturing is limitless, we are constrained by a lack of comprehensive "materialsproduct-manufacturing" principles, guidelines and standards for best FGAM practices. Suitable methodologies have yet to be established to fully enable and exploit the true potential of FGAM on a commercial or economic scale. A global approach is required from sectors across the digital chain to tackle the connected fundamental issues to encourage a mainstream use of FGAM.

\section{References}

[1] N. Oxman, S. Keating, E. Tsai, Functionally Graded Rapid Prototyping, Mediated Matter Group, MIT Media Lab, 2011.

[2] R.M. Mahamood, E.T. Akinlabi, Functionally graded materials, Topics in Mining, Metallurgy and Materials Engineering, Springer, 2017, https://doi.org/10.1007/978-3-31953756-6.

[3] N. Oxman, Variable property rapid prototyping, Virtual Phys. Prototyp. 6 (1) (2011) 3-31 77 Mass. Ave., E14-433C, Cambridge, MA, 02139-4307, USA.

[4] A.O. Aremu, J.P.J. Brennan-Craddock, A. Panesar, I.A. Ashcroft, R.J.M. Hague, R.D. Wildman, C. Tuck, A voxel-based method of constructing and skinning conformal and functionally graded lattice structures suitable for additive manufacturing, Addit. Manuf. 13 (2017) (2016) 1-13.

[5] S. Keating, Design Brief: Select Projects from Steven Keating, (2015) (Accessed 24 November 2017), http://www.stevenkeating.info/stevenkeatingdesignbrief.pdf.

[6] J.W. Choi, H.C. Kim, R. Wicker, Multi-material stereolithography, J. Mater. Process. Technol. 211 (2011) 318-328.

[7] Sirris, Potential of Functional Graded Materials (FGM), (2012) (Accessed 24 November 2017), https://www.slideshare.net/sirris_be/2012-1115highvlauemanufacturingsirrismagnien.

[8] S. Tamas-Williams, I. Todd, Design for additive manufacturing with site-specific properties in metals and alloys, Scripta Materialia (2016) 135 (2016) 105-110.

[9] V. Birman, L.W. Byrd, Modelling and analysis of functionally graded materials and structure, ASME Appl. Mech. Rev. 60 (5) (2007) 195-216.

[10] E.S. Chauhan, Fracture of Functionally Graded Materials, (2016) (Accessed 24 November 2017), https://www.slideshare.net/ErShambhuChauhan/functionallygradedmaterial. 
[11] J. Hascoet, P. Muller, P. Mognol, Manufacturing of complex parts with continuous functionally graded materials (FGM), Proceedings of the Solid Freeform Fabrication Symposium, (2011), pp. 557-569.

[12] B. Kieback, A. Neubrand, H. Riedel, Processing techniques for functionally graded materials, Mater. Sci. Eng. 362 (1-2) (2003) 81-106.

[13] M. Vaezi, S. Chianrabutra, B. Mellor, S. Yang, Multiple material additive manufacturing-part 1: a review virtual and physical prototyping, Virtual Phys. Prototyp. 8 (1) (2013) 19-50.

[14] F. Craveiro, H. Bartolo, P. Bartolo, Functionally graded structures through building manufacturing, Adv. Mater. Res. 683 (2013) 775-778.

[15] P. Muller, J.Y. Hascoet, P. Mognol, Toolpaths for additive manufacturing of functionally graded materials (FGM) parts, Rapid Prototyp. J. 20 (6) (2014) 511-522.

[16] P. Muller, J.Y. Hascoet, P. Mognol, Functionally graded material (FGM) parts: from design to the manufacturing simulation, Proceedings of the ASME 2012 11th Biennial Conference on Engineering Systems Design and Analysis ESDA2012 July 2-4, Nantes, France. ESDA2012-82586, 2012.

[17] General Fabb, 3D Design Futures: An Interview With Dr. Daniel Richards, Part 2, 17 January, (2018) (Accessed 28 February 2018), http://www.fabbaloo.com/blog/2018/1/17/3ddesign-futures-an-interview-with-dr-daniel-richards-part-2.

[18] F. Xerox, The New 3D Data Format FAV, (2017) (Accessed 22 November 2017), http://www.fujixerox.com/eng/company/technology/communication/3d/fav.html.

[19] B. Zhang, P. Jaiswal, R. Rai, S. Nelaturi, Additive manufacturing of functionally graded objects: a review August 21-24, Proceedings of the ASME 2016 International Design Engineering Technical Conferences and Computers and Information in Engineering Conference IDETC/CIE 2016, Charlotte, North Carolina, 2016.

[20] K. Grigoriadis, Mixed Matters: The Epistemology of Designing With Functionally Graded Materials, (2016) (Accessed 26 February 2018), https://www.rca.ac.uk/students/kostasgrigoriadis-13281/.

[21] P. Kulkarni, A. Marsan, D. Dutta, A review of process planning techniques in layered manufacturing, Rapid Prototyp. J. 6 (1) (2000) 18-35.

[22] N.N. Khumbar, A.V. Mulay, Post processing methods used to improve surface finish of products which are manufactured by additive manufacturing technologies: a review, J. Inst. Eng. (India): Series C (2016) 1-7.

[23] S. Bashayam, K. Hoon Shin, D. Dutta, An integrated CAD system for design of heterogeneous objects, Rapid Prototyp. J. 6 (2) (2000) 119-135.

[24] C. Comotti, D. Regazzoni, C. Rizzi, A. Vitali, Additive manufacturing to advance functional design: an application in the medical Field, ASME. J. Comput. Inf. Sci. Eng. 17 (3) (2017), https://doi.org/10.1115/1.4033994 031006-031006-9.

[25] J.S. Gero, U. Kannengiesser, The situ behaviour-structure framework, Des. Study 25 (4) (2004) 373-391.

[26] A.A. Requicha, Representations of Rigid Solid Objects, Springer, 1980.

[27] V. Kumar, D. Burns, D. Dutta, C. Hoffmann, A framework for object modeling, Comput.Aided Des. 31 (9) (1999) 541-556.

[28] E. Doubrovski, E. Tsai, D. Dikovsky, J. Geraedts, H. Herr, N. Oxman, Voxel-based fabrication through material property mapping: a design method for bitmap printing, Comput.-Aided Des. 60 (2015) 3-13.

[29] K.H. Shin, D. Dutta, Constructive representation of heterogeneous objects, J. Comput. Inf. Sci. Eng. 1 (3) (2001) 205-217. 
[30] X. Kou, S. Tan, A hierarchical representation for heterogeneous object modelling, Comput.-Aided Des. 37 (3) (2005) 307-319.

[31] D. Richards, M. Amos, Kostas Grigoriadis (Ed.), Encoding Multi-Materiality. Mixed Matters: a Multi-Material Design Compendium, Jovis, 2016, pp. 40-49.

[32] Duann, Shapeways laynches SVX, a Voxel Based File Format for 3D Printing, (2014) (Accessed 25 February 2018), https://www.shapeways.com/blog/archives/17972shapeways-launches-svx-voxel-file-format-for-3d-printing.html.

[33] D. Richards, M. Amos, Designing with gradients: bio-inspired computation for digital fabrication, ACADIA 2014: Design Agency, University of Southern California, Los Angeles, USA, 2014 October 23-25.

[34] J.C. Steuben, A.P. Illiopoulos, J.G. Michopoulos, Implicit slicing for functionally tailored additive manufacturing, Computer-Aided Design. 77 (2016) 107-119.

[35] X. Wu, W. Liu, M.Y. Wang, A cad modelling system for heterogeneous objects, Adv. Eng. Soft. 39 (5) (2008) 444-453.

[36] AbFab3D, SVX Format, (2014) (Accessed 25 February 2018), https://abfab3d.com/svxformat/.

[37] MF Consortium, 3MF, http://www.3mf.io/what-is-3mf/, http://www.3mf.io/faq/ (Accessed 24 November 2017) (2016).

[38] ISO/ ASTM 52900, Additive Manufacturing - General Principles - Terminology, BSI Standards Publication, 2015 BS ISO/ASTM 52900:2015.

[39] M.S. Mason, T. Huang, R.G. Landers, M.C. Leu, Aqueous-based extrusion oh high solids loading ceramic pastes: process modelling and control, J. Mater. Process. Technol. 209 (6) (2009) 2946-2957.

[40] L. Li, Q. Sun, C. Bellehumeur, P. Gu, Composite modeling and analysis for fabrication of FDM prototypes with locally controlled properties, J. Manuf. Process. 4 (2) (2002) 129141.

[41] M. Srivastava, S. Maheshwari, T.K. Kundra, Virtual modelling and simulation of functionally graded material component using FDM technique, Mater. Today: Proc. 2 (4-5) (2015) 3471-3480.

[42] H. Chung, S. Das, Functionally graded nylon-11/silica nanocomposites produced by selective laser sintering, Mater. Sci. Eng. 487 (1-2) (2008) 251-257.

[43] T. Trainia, C. Mangano, R.L. Sammons, F. Mangano, A. Macchib, A. Piattelli, Direct Laser-Metal Sintering as a New Approach to Fabrication of an Isoelastic Functionally Graded Material for the Manufacture of Porous Titanium Dental Implants, Dent. Mater. 24 (2008) 1525-1533.

[44] N. Sudarmadji, J.Y. Tan, K.F. Leong, C.K. Chua, Y.T. Loh, Investigation of the mechanical properties and porosity relationships in selective laser-sintered polyhedrals for functionally graded scaffolds, Acta Biomaterialia 7 (2011) 530-537.

[45] C. Zhou, Y. Chen, Z. Yang, B. Khoshnevis, Digital material fabrication using mask image projection-based stereolithography, Rapid Prototyp. J. 19 (3) (2013) 153-165.

[46] K.A. Mumtaz, N. Hopskinson, Laser melting functionally graded composition of waspaloy and zirconia powders, J. Mater. Sci. 42 (18) (2007) 7647-7656.

[47] I. Maskery, N.T. Aboulkhair, A.O. Aremu, C.J. Tuck, I.A. Ashcroft, R.D. Wildman, R.J.M. Hague, A mechanical property evaluation of graded density Al-Si10-Mg lattice structures manufactured by selective laser melting, Mater. Sci. Eng.: A 670 (2016) 264-274.

[48] C. Anstaett, C. Seidel, G. Reinhart, Fabrication of 3D-multi-material parts by laser based powder bed fusion, Solid Free Form Fabrication Proceedings, (2017). 
[49] C.K. Chua, K.F. Leong, 3D Printing and Additive Manufacturing: Principles and Application, fourth ed., World Scientific, Singapore, 2014.

[50] I. Gibson, D.W. Rosen, B. Stucker, Additive Manufacturing Technologies: Rapid Prototyping to Direct Digital Manufacturing, 1st ed., Springer, New York, 2010.

[51] X. Tan, Y. Kok, Y.J. Tan, G. Vastola, Q.X. Pei, G. Zhang, Y.W. Zhang, S.B. Tor, K.F. Leong, C.K. Chua, An experimental and simulation study on build thickness dependent microstructure for electron beam melted Ti-6Al-4V, J. Alloys Compd. 646 (2015) 303-309.

[52] B.E. Caroll, R.A. Otis, J.P. Borgonia, A.M. Beese, Functionally graded material of 304L stainless steel and inconel 625 fabricated by directed energy deposition: characterization and thermodynamic modelling, Acta Mater. 108 (2016) 46-54.

[53] S. Kumar, Development of functionally graded materials by ultrasonic consolidation, CIRP J. Manuf. Sci. Technol. 3 (1) (2010) 85-87.

[54] Stratasys, PolyJet Digital Materials, (2017) (Accessed 24 November 2017), http:// www.stratasys.com/materials/polyjet/digital-materials.

[55] S.A.M. Tofial, E.P. Koumoulos, A. Bandyopadhyay, S. Bose, L. O'Donoghue, C. Charitidis, Additive manufacturing: scientific and technological challenged, market uptake and opportunities, Mater. Today 21 (1) (2017) 22-37.

[56] S. Lim, Developments in construction-scale additive manufacturing processes, Autom. Constr. 21 (2011) 262-268.

[57] N. Oxman, E. Tsai, M. Firstenberg, Digital anisotropy: a variable elasticity rapid prototyping platform, Virtual Phys. Prototyp. 7 (4) (2012) 261-274.

[58] S. Tibbit, 4D Printing. MIT Self-Assembly Lab and Stratasys, (2013) (Accessed 27 February 2018), http://www.selfassemblylab.net/4DPrinting.php. 